\title{
Effect of Alkali-modified Kenaf Fiber Incorporation on the Biodegradability and Hydrolytic Degradability of Used Polyethylene Material
}

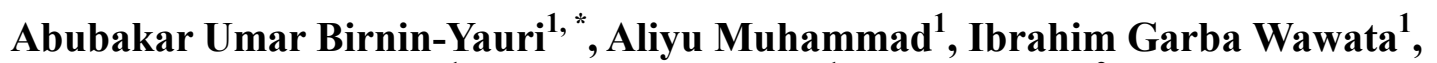 \\ Hannatu Abubakar Sani ${ }^{1}$, Mustapha Maccido ${ }^{1}$, Aminu Umar ${ }^{2}$, Sayudi Haruna Yahaya ${ }^{1}$, \\ Ahmad Umar ${ }^{1}$ \\ ${ }^{1}$ Department of Pure and Applied Chemistry, Faculty of Physical Sciences, Kebbi State University of Science and Technology, Aleiro, \\ Nigeria \\ ${ }^{2}$ Department of Biochemistry, Faculty of Life Sciences, Kebbi State University of Science and Technology, Aleiro, Nigeria
}

Email address:

abubkumar@gmail.com (A. U. Birnin-Yauri)

${ }^{*}$ Corresponding author

\section{To cite this article:}

Abubakar Umar Birnin-Yauri, Aliyu Muhammad, Ibrahim Garba Wawata, Hannatu Abubakar Sani, Mustapha Maccido, Aminu Umar, Sayudi Haruna Yahaya, Ahmad Umar. Effect of Alkali-modified Kenaf Fiber Incorporation on the Biodegradability and Hydrolytic Degradability of Used Polyethylene Material. American Journal of Polymer Science and Technology. Vol. 6, No. 1, 2020, pp. 1-9.

doi: 10.11648 j.ajpst.20200601.11

Received: July 20, 2020; Accepted: July 29, 2020; Published: August 20, 2020

\begin{abstract}
Polyethylene (PE)-based plastic wastes are non-biodegradable and tend to persistently disturb and destroy the environment. The novel approach in this research is incorporation of alkali-modified kenaf fiber into the used PE material aiming at improving its biodegradability and hydrolytic degradation. The alkaline modification of the kenaf fiber was achieved using 5 wt. \% sodium hydroxide $(\mathrm{NaOH})$ solution as revealed by chemical composition analysis and Fourier Transformed Infrared Spectroscopy of the alkali-treated fiber. Melt-blending approach was employed to fabricate composites using both treated and un-treated kenaf fibers together with the used low density PE, in the form of table water sachets, at various fiber-toPE loading formulations. Characterizations of these composites were conducted for their biodegradability using Sandy soil. Additional characterizations conducted included hydrolytic degradation and thermogravimetric analysis respectively. In the results obtained for biodegradation and hydrolytic degradation, the alkali treated kenaf fiber-PE composites revealed a more promising performance than its corresponding un-treated kenaf fiber-PE composites. The higher the kenaf fiber the higher the biodegradation and hydrolytic degradation respectively. These composites also showed higher hydrolytic degradation as well as higher thermal stability in comparison to their corresponding un-treated kenaf fiber-PE composites. The findings on Analysis of Variance (ANOVA) revealed that alkali-modified kenaf fiber incorporated PE composites showed a more statistically significant results for biodegradation and hydrolytic degradation particularly between 60 to 90 days retention periods.
\end{abstract}

Keywords: Polyethylene, Kenaf Fiber, Biodegradation, Hydrolytic Degradation

\section{Introduction}

Polyethylene (PE) is one of the most widely used petroleumbased thermoplastic polymer in the world owing to its good material properties such as toughness, near-zero moisture absorption, low coefficient of friction, excellent chemical inertness, ease of processing and low electrical conductivity.
These material properties associated with PE enabled its wide spectrum of applications in areas such as pipes, sheet, containers, plastic bags and other products [1]. Recent report shows that over 100 million tons of PE resins are produced annually accounting for $34 \%$ of the total plastic market [2].

Polyethylene (PE) is a typical organic polymer derived from petrochemicals, through addition polymerization of ethene; it is a thermoplastic, elastic and non-toxic polymer. It is non- 
degradable polymer being used extensively in many applications. It is also the first commodity plastic to be used for food packaging which came into general use in the 1950s. Plastic materials account for about $25 \%$ of packaging materials [3]. Since then, it has achieved its dominant position as a packaging material for a wide range of foods and beverages due to its relative low cost, versatile properties and the ease with which it can be manufactured and converted [4].

However, increase of PE threat to the environment which take a long time to decompose, rising concern about plastic waste disposal, new rules and regulation on plastic wastes, the need for more versatile polymer-based material has awaken the researchers around the world to put more interest in finding environmentally degradable polymer material. The biodegradable polymer materials will reduce the need for synthetic polymer production, thus reducing pollution at low cost, thereby producing positive effects both environmentally and economically.

Biodegradable plastics are those materials which undergo a significant change in chemical structure under specific environmental conditions. These changes result in a loss of physical and mechanical properties, as measured by standard methods. Biodegradable plastics undergo degradation from the action of naturally occurring microorganisms such as bacteria, fungi, and algae. Degradation is a process of breaking down a material into its constituent elements by a physical, chemical or a biochemical process which should be irreversible. When this process of degradation is aided by the attack of living matter especially microorganisms, resulting into mineralization or biomass, it becomes biodegradation [5].

Biodegradation is the chemical dissolution or breakdown of materials. It occurs with enzymatic action and involves living organisms (micro/macro). Molecular degradation is promoted by enzymes and can occur under aerobic and anaerobic conditions, leading to complete or partial removal from the environment. Linear polymers are generally more biodegradable than branched polymers. The biodegradability of jute polymer composite has been examined in various environments such as in the soil, compost and weather [6].

The technological advancement in the world is currently geared towards making the world 'green', thus, the need for global participation in saving our environment and making the world cleaner and more habitable [7].

Natural fiber reinforced polymer composite is one sector that attract researchers that are looking for green, biodegradable, ecofriendly and low cost materials. Natural fibers are environmentally friendly, easily obtainable which can be extracted from various part of plant (leaf, bark, stem, and fruit). Among the plant fibers that are widely used as reinforcement include cotton, kenaf, hemp, jute, sisal, etc. Composites constitute of two parts namely- reinforcing material and matrix. Generally, reinforcing materials are strong with low density, and the matrix material is ductile and tough so that the composite can get a combination of both the properties. Composite is a material composed of two or more distinct constituent materials (one being naturally derived), which is combined to yield a new material with improved performance over individual constituent materials. Thermoplastics such as Polyethylene and Polylactic acid have been incorporated with kenaf fiber to prepare polymer composite [8-10].

Kenaf, Hibiscus cannabinus, originally from Africa has traditionally been a source of bast fiber in India and China, which together account for more than 75 percent of world kenaf production. The attractive features of kenaf is that up to 40 percent of the stalk yields usable fiber, roughly twice that of jute, hemp or flax, which makes the fiber quite economical [11].

Kenaf is seen as an herbaceous annual plant that can be grown under a wide range of weather conditions; for example, it grows to more than $3 \mathrm{~m}$ within 3 months even in moderate ambient conditions with stem diameter of $25-51 \mathrm{~mm}$. It is also a dicotyledonous plant meaning that the stalk has three layers; an outer cortical also referred to as ("bast") tissue layer called phloem, an inner woody ("core") tissue layer xylem, and a thin central pith layer which consist of spongelike tissue with mostly non- ferrous cells [12].

Kenaf has the ability to absorb nitrogen and phosphorus in the soil. These minerals are able to help increase the crop height, cumulative weed weight, stem diameter, and fiber yield. Also it transforms carbon dioxide to oxygen at a significantly higher rate as compared to other lignocellulosic fibers. Efficient transformation of carbon dioxide can enhance the photosynthesis rate of fiber. Therefore, kenaf is not only environmentally friendly in terms of its biodegradability, but it produces a lot of oxygen as well as reducing carbon dioxide [13].

Kenaf fiber is a good reinforcing agent in polymer composite due to its high strength and elastic modulus, high stiffness, low density, low cost and eco-efficient, less health hazards, renewability, good mechanical and thermal properties, and biodegradability. It is traditionally used for rope, twine, fish net and sacking materials. Kenaf fibers are far cheaper when compared with carbon fiber and glass fiber. The price of kenaf fiber per $\mathrm{kg}$ is $0.53 \mathrm{US} \$$ as against glass fiber and carbon fiber which are 3.25 US\$ and 500 US\$ per kg respectively [14].

The use and production of composite materials has grown extensively and has brought positive advantages for the manufacturing and industrial sectors over traditional reinforcing fibers like glass and carbon. However, the main drawback of natural fibers is that their hydrophilic property reduces their compatibility with hydrophobic polymer matrix during composite fabrication. As a result, the poor fibermatrix adhesion causes reduced mechanical properties. Therefore, it is necessary to improve the mechanical and other properties of the composites by introducing chemical treatments (such as maleic anhydride, isocyanates, organosilanes, permanganate peroxide, sodium hydroxide etc.) and physical treatments (corona treatment and cold plasma treatment) to the natural fibers [14-15].

Alkaline treatment or mercerization is one of the most used chemical treatments of natural fibers. The aim of the modification done by alkaline treatment is the disruption of hydrogen bonding in the network structure, thereby increasing surface roughness. This treatment removes a 
certain amount of lignin, wax and oils covering the external surface of the fiber cell wall, depolymerizes cellulose and exposes the short length crystallites. This improves the adhesion between the fiber surface and the polymer matrix, increases fiber strength and reduces water absorption by the composites (increasing moisture resistance), and improve their mechanical properties. More so, addition of aqueous sodium hydroxide $(\mathrm{NaOH})$ to natural fiber promotes the ionization of the hydroxyl group to the alkaoxide [16-18]. The chemical reaction between $\mathrm{NaOH}$ and natural fiber is assumed to take place as presented in the equation (1).

Fiber $-\mathrm{OH}+\mathrm{NaOH} \rightarrow$ Fiber $-\mathrm{O}-\mathrm{Na}+\mathrm{H}_{2} \mathrm{O}$

In this study, an attempt was made to chemically modify the kenaf fiber using alkalization approach and determine the chemical composition of both treated and un-treated kenaf fibers. The alkali-treated and un-treated kenaf fiber would be used as reinforcement into the used PE as matrix to fabricate composite through melt-blending approach using different mixing ratios. Characterizations of these fabricated composite materials would be conducted for their thermal stability, hydrolytic degradability and biodegradability respectively.

\section{Material and Methods}

\subsection{Sample Collection and Preparation}

The kenaf fiber was collected and prepared as depicted in figure 1a through 1f. Initially, the kenaf plant was collected from Sayya Gidan Gada in Wamakko Local Government Area of Sokoto State, Nigeria. The leaves were removed, stalks cut, the bast fibers were peeled and air-dried. The kenaf fibers were thereafter immersed in tap water for 24 hours, and then separated into thin filament using a sharp metal (knife, needle etc).

The kenaf fibers were then cut into pieces, and then reduced to small sizes with a grinding machine, followed by sieving into fiber sizes ranging from 300 to $400 \mu \mathrm{m}$. In order to remove impurities, the kenaf fibers were physically treated by sorting and soaking in distilled water for $24 \mathrm{~h}$ at $25^{\circ} \mathrm{C}$ and washed with heated water at $60^{\circ} \mathrm{C}$, cleaned with acetone (analytical grade, $99.5 \%$ purity), and oven-dried at $60^{\circ} \mathrm{C}$ for $48 \mathrm{~h}[9,19]$.

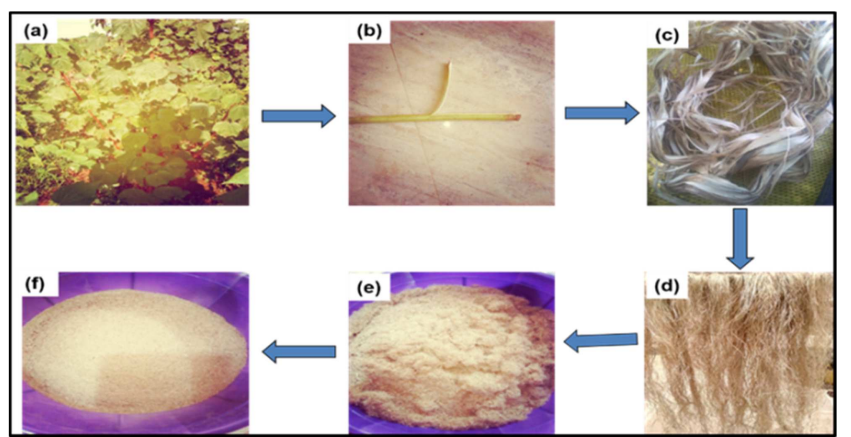

Figure 1. Kenaf plant (a); Kenaf stalk (b); Kenaf fiber (c); Combed kenaf fiber (d); Pulverized Kenaffiber (e) and Sieved Kenaffiber (f).
Similarly, the used PE in the form of used table water sachets (Figure 2) were collected from Mini Market area in Kebbi State University of Science and Technology Aliero, Nigeria. The collected materials were cut into small pieces and washed with detergent, rinsed with distilled water several times and then oven-dried. The dried samples were kept in desiccator until it is required for further analyses.

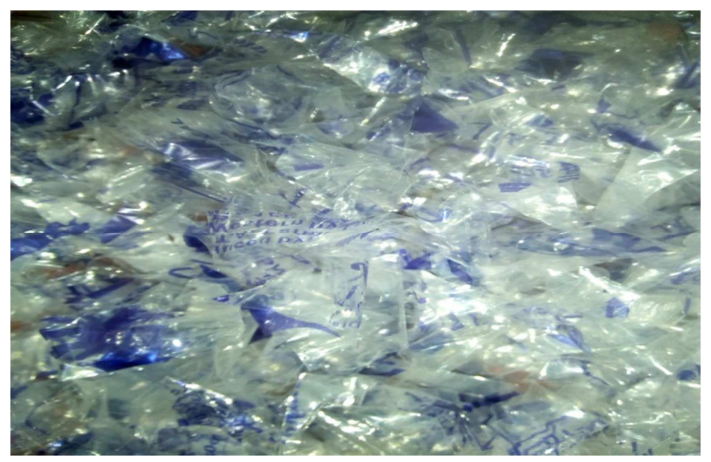

Figure 2. Used PE-based Table water sachets.

\subsection{Modification of Natural Fibers Using Aqueous Sodium Hydroxide Solution}

A 40 g purified kenaf fibers was chemically treated by soaking in 5 wt. \% aqueous sodium hydroxide solution. The $\mathrm{pH}$ of the solution was regulated until it reaches 9.1. The mixture was maintained at $25^{\circ} \mathrm{C}$ for $24 \mathrm{~h}$.

The treated fibers (Figure 3) was filtered thoroughly, washed with distilled water until a neutral $\mathrm{pH}$ was obtained (i.e. $\mathrm{pH}=7.10$ ). Thereafter, the treated fibers were oven-dried at $60^{\circ} \mathrm{C}$ for $24 \mathrm{~h}$. The dried fibers were stored in sealed plastic bags at $25^{\circ} \mathrm{C}$ for subsequent investigations in accordance with the previous methods $[9,18]$.

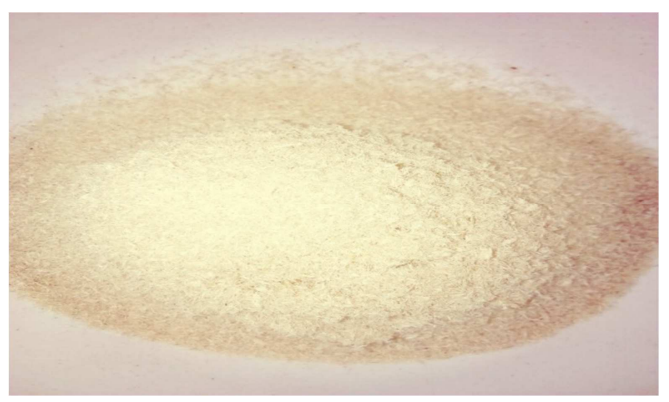

Figure 3. Sodium hydroxide modified Kenaf fiber.

\subsection{Determination of Physicochemical Composition of Treated and Un-treated Fibers}

To determine the holocellulose i.e. cellulose and hemicellulose contents, the sodium hydroxide treated and untreated kenaf fibers were reacted with acidified aqueous sodium chlorite $\left(\mathrm{NaClO}_{2}\right)$ solution to delignify the fibers, the $\mathrm{NaClO}_{2}$ solution was acidified with a $\mathrm{H}_{2} \mathrm{SO}_{4}$ solution until a $\mathrm{pH}$ of 4 is reached.

Thereafter, $1 \mathrm{~g}$ each of the fibers were soaked in $5 \mathrm{wt}$ \% $\mathrm{NaClO}_{2}$ solutions at $70^{\circ} \mathrm{C}$ for $1 \mathrm{~h}$, at a weight ratio of $1: 20$ fiber-to- $\mathrm{NaClO}_{2}$ solution. Once the treatment is complete, the 
fibers were filtered and washed thoroughly with distilled water and oven-dried at $60^{\circ} \mathrm{C}$ until a constant weight is achieved. The cellulose content was determined by treating the $1 \mathrm{~g}$ holocellulose with $6 \mathrm{wt}$. \% potassium hydroxide solution at $25^{\circ} \mathrm{C}$ for $24 \mathrm{~h}$, the mixture is then filtered, and the solid residue obtained was washed thoroughly with distilled water and oven-dried at $60^{\circ} \mathrm{C}$ until a constant weight is obtained. Afterwards, the observed difference between holocellulose and cellulose contents was recorded as the hemicellulose contents of the fibers.

However, the lignin content was determined by submerging $1 \mathrm{~g}$ of sodium hydroxide-treated and un-treated kenaf fiber in $72 \mathrm{wt} \% \mathrm{H}_{2} \mathrm{SO}_{4}$ at $30^{\circ} \mathrm{C}$ for $1 \mathrm{~h}$, then the solution was diluted to $3 \% \mathrm{H}_{2} \mathrm{SO}_{4}$ and refluxes for $2 \mathrm{~h}$, the mixture was filtered and the insoluble solid residue obtained was washed thoroughly with distilled water and oven-dried at $60^{\circ} \mathrm{C}$ until a constant weight is obtained. All the above mention analyses were carried on average of triplicate.

Moreover, the moisture content was determined by placing $2 \mathrm{~g}$ of kenaf fiber (both treated and un-treated) in an oven at $105^{\circ} \mathrm{C}$ for $4 \mathrm{~h}$, after that the weights of oven-dried samples were recorded. Then the moisture content was calculated by obtaining the difference between the weights of the fiber before and after oven-drying.

The ash content was determine by weighing $2 \mathrm{~g}$ of kenaf fiber (both treated and un-treated) and heated in a furnace at $600^{\circ} \mathrm{C}$ for $2 \mathrm{~h}$, after which the fibers were cooled in a desiccator and re-weighed. The ash content was calculated as the difference between the weight of the fiber before and after furnace heating.

\subsection{Fabrication of Kenaf fiber-PE Composites}

Melt-blending approach was employed to fabricate the composite materials. Initially, a metal plate was heated on a hot plate set at $120^{\circ} \mathrm{C}$. The measured amount of the PE was added to melt for 15 minutes followed by addition of a measured amount of the kenaf fiber. The mixture was mechanically stirred for 30 minutes. The thoroughly mixed fiber-PE was then placed in a mold having $1 \times 5 \times 10 \mathrm{~mm}^{3}$ (Thickness $\times$ Width $\times$ Length) dimension. After cooling and solidification, the composites were removed from the mold and stored in a sealed plastic bags for further analysis (Figure 4). This composite fabrication method is a modified procedure of the previous method reported in literature [9]. Both the treated and un-treated kenaf fiber reinforced PE composites were respectively fabricated following the stated procedure at a fiber-to-PE mixing formulations presented in Table 1.

Table 1. Kenaf fiber to P. E mixing formulations.

\begin{tabular}{lll}
\hline SN & Kenaf fiber $(\mathbf{\%})$ & PE $(\%)$ \\
\hline 1 & - & 100 \\
2 & 95 & 5 \\
3 & 90 & 10 \\
4 & 85 & 15 \\
5 & 80 & 20 \\
6 & 75 & 25 \\
\hline
\end{tabular}

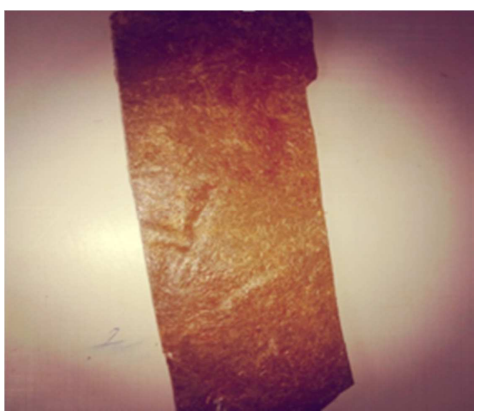

Figure 4. Fabricated Kenaf fiber-PE composite.

\subsection{Fourier Transform Infrared Spectroscopy}

The functional groups and chemical characteristics of treated and un-treated kenaf fibers were obtained by Fourier Transform Infrared Spectroscopy (FTIR) (Prestige21 Shimadzu, Japan) with a resolution of $4 \mathrm{~cm}^{-1}$ in a spectral range of $4000-600 \mathrm{~cm}^{-1}$ using 32 scans per sample [12].

\subsection{Thermogravimetric Analysis}

It is important to investigate the decomposition and degradation of composites at higher temperature, especially if these materials are intended for use in food packaging applications. Low levels of degradation products produced during the thermal processing of such polymers may taint and/or contaminate foodstuffs upon contact, thereby causing concerns regarding organoleptic properties or indeed safety. Furthermore, the thermal stability of these materials is also of relevance to the ultimate disposal in composting or land fill where degradation usually takes place at elevated temperatures [20].

Thermogravimetric analysis (TGA) is a technique that uses heat to bring about reactions and physical changes in materials or substance, TGA allows the determination of the mass of composites lost due to temperature or thermal degradation. TGA was also used to determine the thermal stability of the composites. The TGA of pure PE and treated and un-treated kenaf-PE composites was conducted using DTG-60AH thermogravimetric analyzer. The temperature ranged from $30^{\circ} \mathrm{C}$ to $800^{\circ} \mathrm{C}$, at a heating rate of $10^{\circ} \mathrm{C} \mathrm{min}-{ }^{1}$ under nitrogen atmosphere [21].

\subsection{Hydrolytic Degradation Test}

The long-term hydrolytic degradation was performed by immersing the samples under hydrolytic conditions for up to 90 days; the specimen samples of the kenaf-PE composites were immersed in water and stored in a humidified condition at $37^{\circ} \mathrm{C}$. At each specific incubation time (monthly), weights of the composite materials were measured and recorded.

\subsection{Biodegradability Test}

Biodegradability test was conducted through soil burial approach on a laboratory scale. The sample specimens were cut from both the treated and un-treated kenaf-PE composites having $1 \times 5 \times 10 \mathrm{~mm}^{3}$ dimensions. Biodegradability of the samples was studied by weight loss over time in a soil 
environment. The sample was buried in the sandy soil for up to 90 days.

The soil was maintained at approximately $20 \%$ moisture by injecting water to keep the microorganisms active and samples was buried at a depth of $3-5 \mathrm{~cm}$ with a $5.5 \mathrm{pH}$ range. The buried samples were dug out at 30 day's intervals throughout the time, washed with water and acetones, dried in a vacuum oven at $50 \pm 1{ }^{\circ} \mathrm{C}$ for $24 \mathrm{~h}$ before evaluation. The samples will then weigh to determine the weight loss. [22-23].

\subsection{Statistical Analysis}

One-way analysis of variance (ANOVA) was conducted to determine the statistical difference between the mean values for the biodegradation and hydrolytic degradation of the composites materials.

\section{Results}

The hydrolytic degradation and biodegradation of the alkali-treated and un-treated kenaf fiber reinforced PE composites were investigated. The results of FTIR analysis obtained from treated and un-treated kenaf fiber is presented in Figure 5. The results on physicochemical composition of alkali-treated and un-treated kenaf fibers is presented in Table 2. The results on TGA of the composites are given in Figure 6. The results on hydrolytic degradation and biodegradation of the composites are depicted in Figures 7 and 8 respectively. The results on the Anova tests for hydrolytic degradation and biodegradability of the treated and un-treated kenaf-PE composites are presented in Tables 3 and 4 respectively.

Table 2. Physicochemical composition of alkali-treated and un-treated kenaf fibers.

\begin{tabular}{lll}
\hline Parameter & Treated kenaf (\%) & Un-treated kenaf (\%) \\
\hline Holocellulose & 85.6 & 79.2 \\
Cellulose & 72.7 & 64.4 \\
Hemicellulose & 12.9 & 14.8 \\
Lignin & 29.8 & 9.8 \\
Moisture & 30.67 & 31.3 \\
Ash & 8 & 8.7 \\
\hline
\end{tabular}

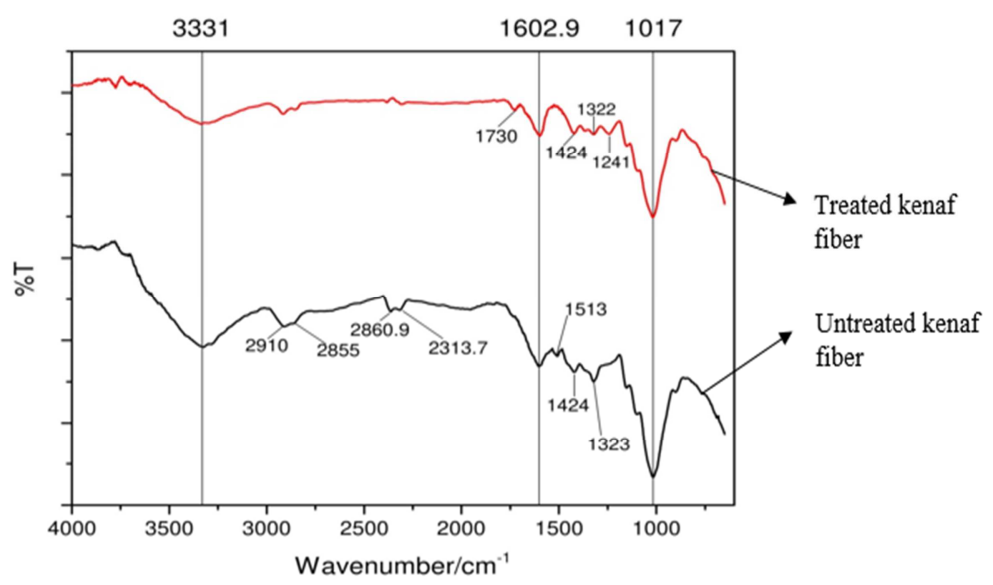

Figure 5. FT-IR spectra of treated and un-treated kenaf fiber.

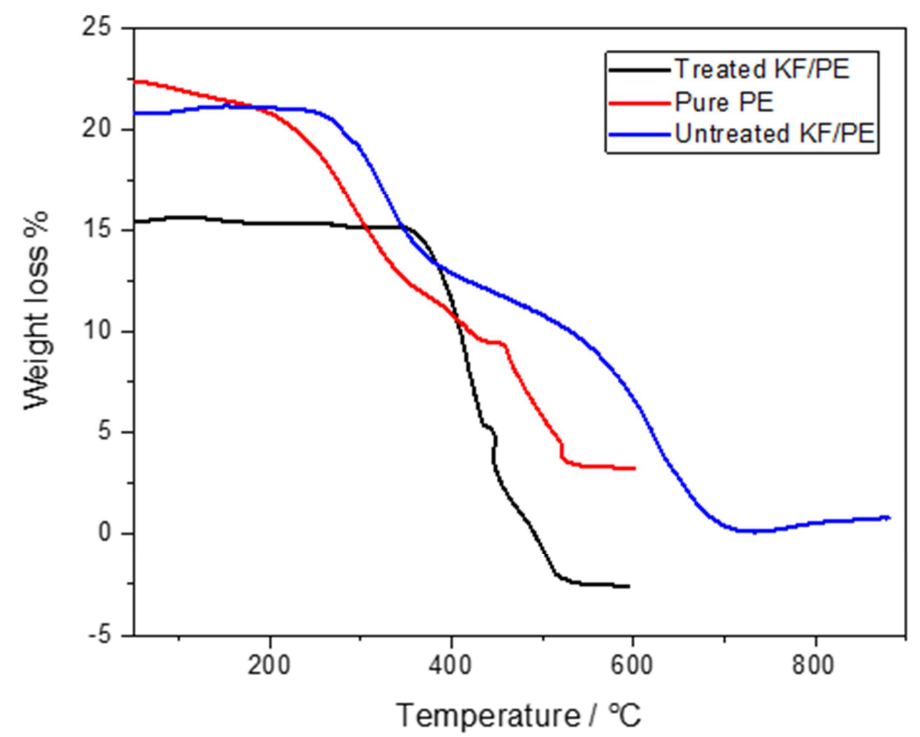

Figure 6. TGA thermograms of treated and un-treated kenaf fiber-PE composites. 

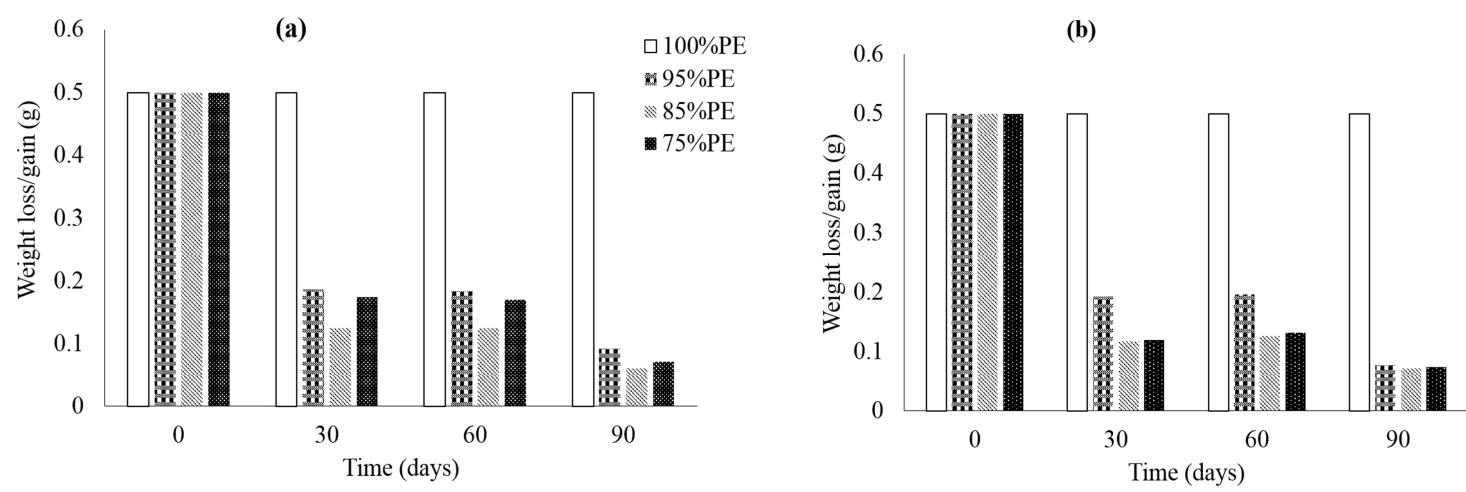

Figure 7. Hydrolytic degradation of treated kenaf fiber-PE composites (a) and un-treated kenaf fiber-PE composites (b).

(a)

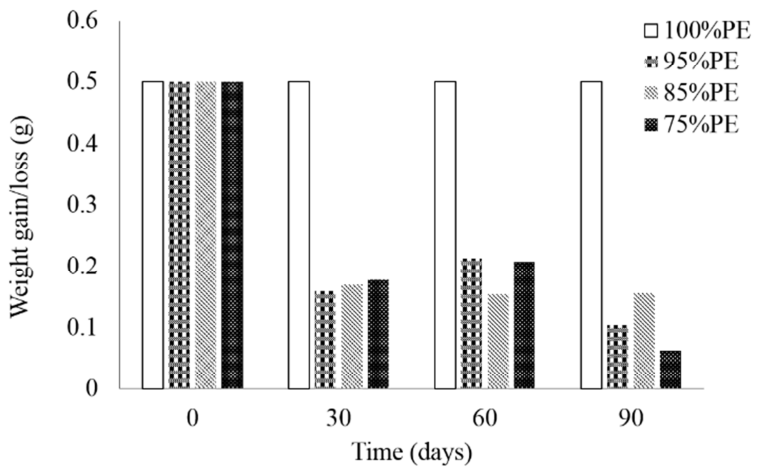

(b)

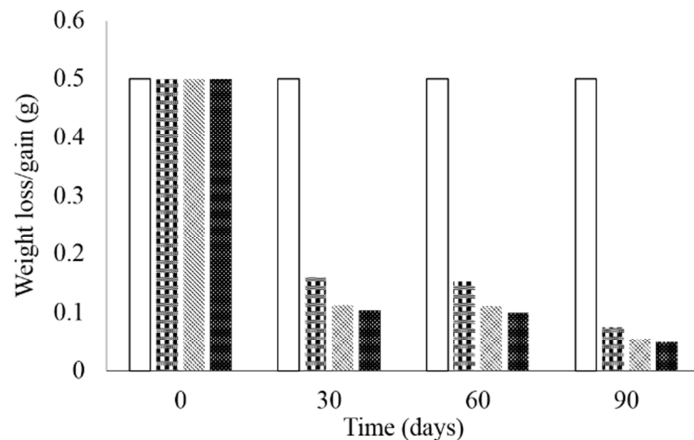

Figure 8. Biodegradation of treated kenaffiber-PE composites (a) and un-treated kenaffiber-PE composites (b).

Table 3. Anova test for hydrolytic degradation of treated and un-treated kenaf-PE composites.

\begin{tabular}{|c|c|c|c|c|c|c|c|c|}
\hline \multicolumn{5}{|c|}{ Treated kenaf-PE composites } & \multicolumn{4}{|c|}{ Un-treated kenaf-PE composites } \\
\hline Source & Initial & 30 days & 60 days & 90 days & Initial & 30 days & 60 days & 90 days \\
\hline TSS & 0.007772 & 0.012407 & 0.011404 & 0.004015 & 0.021186 & 0.017571 & 0.019796 & 0.001643 \\
\hline SSBG & 0.005171 & 0.008176 & 0.00796 & 0.002773 & 0.017788 & 0.011019 & 0.012331 & 0.000321 \\
\hline DFBG & 2 & 2 & 2 & 2 & 2 & 2 & 2 & 2 \\
\hline DFWG & 9 & 9 & 9 & 9 & 9 & 9 & 9 & 9 \\
\hline F-start & 8.944499 & 8.69587 & 10.40221 & 10.04896 & 23.56124 & 7.56841 & 7.433374 & 0.97163 \\
\hline
\end{tabular}

Table 4. Anova test for biodegradability of treated and un-treated kenaf-PE composites.

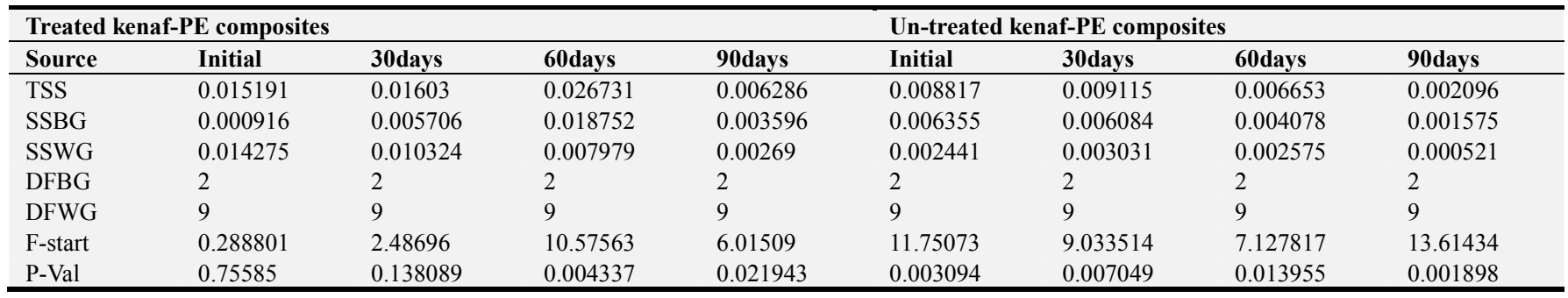

$\mathrm{TSS}=$ Total sum of square; $\mathrm{SSBG}=$ sum of square between group; $\mathrm{SSWG=sum} \mathrm{of} \mathrm{square} \mathrm{within} \mathrm{group;} \mathrm{DFBG}=$ degree of freedom between group; $\mathrm{DFWG}=$ degree of freedom within group; F-test $=\mathrm{F}$ test for ANOVA; P-Value=Probability value; Number of sample=4; Number of observations=24.

\section{Discussion}

The chemical constituents of both the treated and untreated kenaf fibers i.e., cellulose, hemicellulose and lignin were analyzed using FTIR. From the FTIR analysis in Figure 5 , the broad and intense peak for un-treated kenaf fiber at $3331 \mathrm{~cm}^{-1}$ is due to the $\mathrm{OH}$ stretching for hydroxyl group, this corresponded within the range previously reported [24]. The O-H stretching in the region is decreased after alkaline treatment. This decrease could be attributed to removal of hemicellulose and lignin consequent of the alkali treatment of the fiber.

However, the weak peak which is at $1602.9 \mathrm{~cm}^{-1}$ in untreated kenaf fiber is due to the presence of hemicellulose 
and can be assigned to the $\mathrm{C}=\mathrm{O}$ stretching. This peak absorbance intensity decreases after sodium hydroxide treatment suggesting the partial removal of hemicellulose from the fiber. This agreed with the previous findings reported elsewhere [25-26].

The $1730 \mathrm{~cm}^{-1}$ is the characteristic for the stretching vibration of an unconjugated $\mathrm{C}=\mathrm{O}$ group in the acetyl group in hemicellulose, this peak has partially disappeared after the treatment with sodium hydroxide which also indicates the removal of hemicellulose, pectin and wax that is present on the kenaf fiber. Also the bands at $1424 \mathrm{~cm}^{-}{ }^{1}$ and $1322 \mathrm{~cm}^{-}{ }^{1}$ are assigned to $-\mathrm{CH}_{3}$ asymmetric and $\mathrm{C}-\mathrm{H}$ symmetric deformations of lignin in un-treated kenaf fiber respectively. These peaks appeared weak in sodium hydroxide treated kenaf fiber which also indicates partial removal of lignin.

These FTIR findings corroborated with the results of chemical constituents of the kenaf fiber presented in Table 2, it can be seen that the hemicellulose contents have decreased in the alkali treated kenaf fiber compared to the un-treated fibers. Removal of hemicellulose increased the relative amount of cellulose composition on the treated fibers. These results indicated that, sodium hydroxide treatments dissolved hemicellulose and lignin constituents from the fibers. Also ash content was lower in sodium hydroxide treated kenaf fiber compared to the un-treated kenaf fiber, and this implies removal of hemicellulose and lignin.

The low moisture content in alkali treated kenaf fiber compared to the un-treated kenaf fiber show that the hygroscopicity of the lignocellulosic material is reduced as can be seen in Table 2. This indicated that the removal of some hydroxyl groups (i.e. hemicellulose) on the cell wall polymers with bonded chemical groups which will pave the way for direct bonding between cellulose micro fibrils and the polymer matrix.

The thermal stabilities of both the alkali-treated and untreated kenaf reinforced PE composites were analyzed using TGA, the thermograms are presented in Figure 6. The TGA measured the reduction in weight percentage due to decomposition or degradation of a polymer composite with respect to time and temperature. The reduction in weight percentage versus increase in temperature plot for representative samples viz. pure PE, 75\% treated kenaf fiber$\mathrm{PE}$ and $75 \%$ un-treated kenaf fiber-PE composites is investigated.

The pure PE showed a one-step decomposition process, while treated kenaf-PE composite and un-treated kenaf fiberPE composite showed a two-step decomposition process respectively. The composites showed higher initial degradation temperatures (Tonset), as well as maximum temperature of degradation (Tmax) than the pure PE. This suggest that the composites possess higher thermal stability than the pure PE. It can clearly be seen that the alkali-treated kenaf fiber-PE composite presented slightly higher Tonset and Tmax compared to its corresponding un-treated one. This could be due to the alkaline treatment which removed hemicellulose and other fiber impurities from the kenaf fiber, thereby strengthen the fiber-to-PE interface bonding and enhanced its thermal stability. The first decomposition rate with respect to temperature (Tonset) in treated kenaf-PE composites occurred at about $363.10{ }^{\circ} \mathrm{C}$ which correspond to the $3.51 \%$ mass loss, may be due to the decomposition of hemicellulose as a result of breakdown of molecular structure [21, 27].

The degradation of the treated kenaf-PE composite sample occurred at a higher temperature of about $363.10^{\circ} \mathrm{C}$ than the un-treated kenaf-PE composites and pure PE samples. This may be connected to the improvement of interfacial adhesion between fibers and polymers after alkali treatment in which the hydrophilic group (hydroxyl group) of fibers was replaced by the alkaoxide group, and that brings about an increased surface roughness in the kenaf fiber which results in better interface interlocking between the filler and the matrix, subsequently improved the thermal behaviors of the composite [28].

The kenaf fiber may retard the movement of free radicals formed during the initiation of degradation, or it may interact with volatile degradation products and in the process slow down their diffusion out of the sample [15]. During the initial thermal decomposition stage around $144.64^{\circ} \mathrm{C}$, the un-treated kenaf-PE composites mainly undergo evaporation of moisture and waxy substances. The second step at temperature around $437.15^{\circ} \mathrm{C}$, which correspond to $42.90 \%$ mass loss, may be due to the decomposition of hemicellulose and cellulose which usual take place around $200^{\circ} \mathrm{C}$ to $400^{\circ} \mathrm{C}$ as previously reported [29]. However, at the temperature around $740.31^{\circ} \mathrm{C}$ which correspond to $57.10 \%$ mass loss may be due to the decomposition of lignin which is believed to have wide range of temperature ranging from $200{ }^{\circ} \mathrm{C}$ to $700^{\circ} \mathrm{C}$ as reported in the literature [30]. This result shows that thermal stability of kenaf-PE composites has increased due to chemical treatment of the kenaf fiber with 5 wt.\% $\mathrm{NaOH}$.

The long-term hydrolytic degradation was performed by immersing treated and un-treated kenaf-PE composites in water for up to 90 days. The results obtained are presented in Figure 7. It can clearly be seen that the pure PE did not degrade throughout the ageing period of 90 days. This can be attributed to the hydrophobic character of the PE material. The composites materials did not show any degradation from 0 to 30 days. However, the weight losses of both the treated and un-treated kenaf-PE composites were observed from 30 days onwards, and steadily increased especially between 60 to 90 days environmental ageing time. The $75 \%$ and $85 \%$ of the kenaf-PE composites showed higher rate of degradation, particularly for the alkali-treated composites. This implies that the higher the treated kenaf fiber, the higher the hydrolytic degradation of the composites. The kenaf fiber is more readily prone to hydrolytic attack and decompose thereby making the composite to eventually degrade during water immersion.

Biodegradability of the samples was studied by weight loss over time in a sandy soil environment through soil burial approach and monitored for 90 days duration. The results obtained are depicted in Figure 8. The biodegradation of 
kenaf-PE composites of treated and un-treated sample is observed by weight loss over time in the soil environment. It can clearly be seen from Figure 8 that the weight losses of both the treated and un-treated kenaf-PE composites increased especially between 60 to 90 days burial time for the $75 \%$ and $85 \%$ kenaf-PE composites respectively. The pure PE showed no degradation throughout the burial period, this can be ascribed to the inability of the microorganism to degrade the PE material within 90 days retention period.

From Figure 8, it can be observed that $75 \%$ treated kenafPE composite exhibited the highest degradation which starts after 30 days of burial, this could be due to the higher cellulose composition of the alkali-treated kenaf fiber [4]. The higher cellulose composition possessed by the treated kenaf fiber would strengthen the fiber-to-PE interface bonding thus provided larger surfaces for microbial attacks resulting in higher degradation rate which correspond to findings previously reported in literature [6].

This biodegradation results showed that weight loss increases with the increase in kenaf fiber loading in the composites which agreed with previous findings reported [31, 32]. The high biodegradation observed in the treated kenaf$\mathrm{PE}$ composites compared to the un-treated kenaf-PE composites may be due to the chemical treatment which removed lignin, hemicellulose, moisture and waxy substances from the kenaf fiber.

The analysis of variance (ANOVA) was carried out to determine the statistical difference for the hydrolytic and biodegradation of the composite materials, the results are presented in Tables 3 and 4 respectively. It can be seen that the P-values of the kenaf-PE composites were less than 0.05 between 60 to 90 days for both hydrolytic and biodegradation, thus indicates that there are statistical significant difference between the mean of these composites at $95 \%$ confidence limit. Whereas, the P-values of the composites between 0 to 30 days appeared greater than 0.05 , thus indicate that there are no statistical significant difference between the mean of these composites at $95 \%$ confidence limit. This statistical nonsignificance could be due to the presence of remnant of sodium hydroxide which can retard hydrolytic and microbial activities during hydrolytic degradation and biodegradation respectively, or due to poor moisture contents that is suitable for microorganism to function properly.

\section{Conclusion and Recommendation}

\subsection{Conclusion}

Alkaline treatment of kenaf fiber enhanced the quality of the fiber by removal of hemicellulose and lignin thereby increased the cellulose composition. The alkali-treated kenaf fiber-PE gave a more thermally stable composite material. In terms of biodegradation and hydrolytic degradation, the alkali treated kenaf fiber-PE revealed a more promising performance than its corresponding un-treated kenaf fiber-PE composites. The higher the kenaf fiber the higher the biodegradation and hydrolytic degradation respectively. This study revealed that the biodegradation and hydrolytic degradation of PE are potentially viable through kenaf fiber incorporation particularly at higher fiber loading and using alkali-treated kenaf fiber.

\subsection{Recommendation}

It is hereby recommended that further works should be conducted on the mechanical, morphological and physical properties of the kenaf fiber-PE composites. In terms of the biodegradation, additional study should be conducted using different soil environments such as sandy, loamy and clay. Also, chemical solution such as acids, alkalis and salts can be employed to further assess the hydrolytic degradation performances of the composite materials.

\section{Acknowledgements}

The authors would like to thank the Department of Pure and Applied Chemistry and Central Research Laboratory, Kebbi State University of Science and Technology Aliero, as well as Department of Pure and Applied Chemistry, Usmanu Danfodio University Sokoto. The authors also acknowledge the funding support from Tertiary Education Trust Fund (TETFund) Nigeria (grant reference no: TETFund/DESS/UNI/ALIERO/2018/RP/VOL. 1).

\section{References}

[1] Khanam, P. N., and Almaadeed, M. A., (2015). Processing and Characterization of Polyethylene-Based Composites. Journal of Advanced Manufacturing: Polymer and Composites Science. 1 (2) 63-79.

[2] Roland, G., Jambeck, J. R., Lavender law., K. (2017) Production,. Use, and Fate of all Plastics Ever Made. Science Advances 3 (7).

[3] Jayasekara, R., Harding, I., Bowater, I. and Lonergan, G. (2005). Biodegradability of a Selected Range of Polymers and Polymer Blends and Standard Methods for Assessment of Biodegradation. Journal of Polymers and the Environment 13 (3).

[4] Tajeddin, B., Abdul Rahman, R., and Abdulah, L. C., (2009). Mechanical and Morphological Properties of Kenaf Cellulose/LDPE Biocomposites. American-Eurasian Journal Agriculture \& Environmental Science 5 (6): 777-785.

[5] Arshad, K., Mujahid, M., (2011). Biodegradation of Textile Materials. Degree of Master in Textile Technology The Swedish School of Textiles. 05-08.

[6] Siddiquee, K. M., Helali M. M., Gafur M. A., Chakraborty S., (2014). Investigation of an Optimum Method of Biodegradation Process for Jute Polymer Composites. American Journal of Engineering Research (AJER) 3, (01) 200-206.

[7] Kolybaba, M., Tabil, LG., Panigrahi, S., Crerar, W. J., Powell, T., and Wang, B. (2003). Biodegradable Polymers: Past, Present, and Future. The Society for Engineering in Agricultural, Food, and Biological systems 3, (0007). 
[8] Yıldızhan, S., Calık, A., Ozcanli, M., Serin, H., Yıldızhan, S., Calık, A., Ozcanlı, M., and Serin, H., (2018). Bio-composite materials: A Short Review of Recent Trends, Mechanical and Chemical Properties, and Applications. European Mechanical Science, 2 (3) 83-91.

[9] Birnin-Yauri, A. U., Ibrahim, N. A., Zainuddin, N., Abdan, K. Then, Y. Y., and Chieng, B. W (2016). Influence of Kenaf Core Fibre Incorporation on the Mechanical Performance and Dimensional Stability of Oil Palm Fibre Reinforce Poly (lactic acid) Hybrid Bioomposites, BioResourse. 11 (12), 3332-3355.

[10] Dixit, S., Goel, R., Dubey, A., and Bhalavi, T., (2017). Natural Fibre Reinforced Polymer Composite Materials. Polymers from Renewable Resources. 8.

[11] Ismail, H., Hamid A. A and Abubakar, A., (2016). Kenaf Core Reinforced High-density Polyethylene/Soya Powder Composites. Journal of reinforced plastics and composites 29, No. $16 / 2010$.

[12] Sarifuddin, N., Ismail, H., and Ahmad, Z., (2013) The Effect of Kenaf Core Fibre Loading on Properties of Low Density Polyethylene/Thermoplastic Sago Starch/Kenaf Core Fiber Composites. Journal of Physical Science, 24 (2), 97-115.

[13] Ketabchi M. R. (2016). Preparation, Characterisation and Optimisation of Cellulose Nanoparticles from Kenaf Fibre and its Application in Polylactic Acid Reinforcement. Chemical \& Environmental Engineering Department Faculty of Engineering The University of Nottingham United Kingdom. (unpublished).

[14] Adole, A. M., Yatim, J. M., Ramli S. A., Othman, A., and Mizal, NA., (2019). Kenaf Fibre and Its Bio-Based Composites: A Conspectus. Pertanika Journal of Science. \& Technol. 27 (1): 297-329.

[15] Mokhothu, T. H. (2010). Preparation and Characterization of Natural Fibre/Co-Polyester Bio composites. Department of Chemistry Faculty of Natural and Agricultural Sciences Univerity of The Free State (Qwaqwa Campus) 8, (unpublished).

[16] Li, X., Lope, G. T., Panigrahi, S., (2007). Chemical Treatments of Natural Fiber for Use in Natural FiberReinforced Composites. Journal of Polymer Environ 15, 25 33.

[17] Kumar, R., Obrai, S., Sharma., (2011). Chemical Modifications of Natural Fiber for Composite Material. Pelagia Research Library. 2 (4) 219-228.

[18] Chubuike O. M, Ebele C. C., Ifeany, i I. F., Okwuchukwu E. S., Festus O. E., (2017). Study on Chemical Treatments of Jute Fiber for Application in Natural Fiber Reinforced Composites (NFRPC), International Journal of Advanced Engineering Research and Science (IJAERS). 4 (2) 2456-1908.

[19] Pang, C. R., Shanks, R. A., and Dave T. (2014). Bio-composites Based on Cellulose Acetate and Kenaf Fibers: Processing and Properties, AIP Conference Proceedings 1593, 350.

[20] Amin Tawakkal, I. S. M., (2016). Characterizations and Antimicrobial activity of Polylactic Acid/Kenaf Biocomposites containing a Natural Agent. College of
Engineering and Science Victoria University Melbourne, Australia.

[21] Tan, M. Y., Kuan, H. T. N and Lee, M. C., (2017). Characterization of Alkaline Treatment and Fiber Content on the Physical, Thermal, and Mechanical Properties of Ground Coffee Waste/Oxobiodegradable HDPE Composite. International Journal of Polymer Science. 12.

[22] Abdul Amer, Z. J., and Qasim, Saee A., (2015). Soil Burial Degradation of Polypropylene/ Starch Blend. International Journal of Technical Research and Applications 3 (1) 91-96.

[23] Ramachandran, M., and Modi, K. (2018). A Review on Various Characterisation of PLA Based Biodegradable Composites. International Journal on Textile Engineering and Processes 4 (1) 28-29.

[24] Alavudeen, A., Ranji, N., Karthikeyan, S., Thiruchitrambalam, M., Venkateshwaran, N. (2015). Mechanical Properties of Banana/Kenaf Fiber-Reinforced Hybrid Polyester Composites: Effect of Woven Fabric and Random Orientation. Material and Design. 66 246-257.

[25] Sahari, j. and Sapuan, S. M, (2011). Natural Fibre Reinforced Biodegradable Polymer Composites Advance Matter Science 30 166-174.

[26] Schwarzová, I. (2016). Investigation OF Observed Changes in Treated Hemp hurds. GeoScience Engineering. (3) 22-26.

[27] Alvin. R., Malenab, J., Ngo, J. P. S., and Michael Angelo B. (2017). Chemical Treatment of Waste Abaca for Natural FiberReinforced Geopolymer Composite. Materials 2017. 10 (579).

[28] Chung, T. K, Park, J. W, Hyun, J. L, Kwon, H. J, Hyun-Joong Kim, H. J, Lee, Y. K and Yin Tze, W. T. (2018). The Improvement of Mechanical Properties, Thermal Stability, and Water Absorption Resistance of an Eco- Friendly PLA/Kenaf Composite Using Acetylation. Journal of applied science., 8 (376) 10.

[29] Jonoobi, M., Harun, J., Shakeri A., Misra, M., Oksman, K., (2009). Chemical Composition, Crstallinity, and Thermal Degradation of Bleached and Unbleached Kenaf Bast (Hibiscus cannabinus) Pulp and Nanofibers. Bioresources 4 (2), 626-639.

[30] Narkpiban, K., Sakdaronnarong, C., Nimchua, T., Pinmanee, P., Thongkred, P., and Poonsawat, T.(2019). The Effect of Mechano-Enzymatic Treatment on the Characteristics of Cellulose Nanofiber Obtained from Kenaf (Hibiscus cannabinus L) Bark Bio resource. 14 (1), 99-119.

[31] Lilian, V. R. B., Bandeira, J. AV., Scienza, L. C., Zattera, A. J.(2014). Biodegradable Composites: morphology, chemical, Thermal, and Mechanical Properties of Composites of Poly (Hydroxybutyrate-CO-Hydroxyvelerate) with Curaua Fibers After Exposure to Simulated Soil. Journal OF Applied Polymer Science.

[32] Ling, P. A., Ismail, H., Abubakar, A. (2018). Linear Low Density Polyethylene/Poly (Vinyl Alcohol)/Kenaf Composites: Effect of Natural Weathering on Functional Group, Weight Loss Characteristics, and Tensile, Morphological and Thermal Properties. Sains Malaysiana 47 (3) 571-580. 